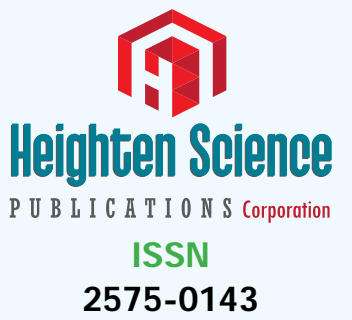

*Address for Correspondence: Dr. Tolga Doğan, MD, Hitit University Çorum Training and Research Hospital, Çorum, Turkey, Yeniyol, Çamlık Cad. No: 2, Çorum/Turkey, Fax: +903642230300; Tel: (90)505 577 2716; Email: tolgadogn@yahoo.com

Submitted: 01 June 2017

Approved: 06 July 2017

Published: 07 July 2017

Copyright: @2 2017 Doğan T, et al. This is an open access article distributed under the Creative Commons Attribution License, which permits unrestricted use, distribution, and reproduction in any medium, provided the original work is properly cited.

Keywords: Coronary artery disease; Fundoscopic examination; Atherosclerosis
Research Article

\section{Investigation of Retinal Microvascular Findings in patients with Coronary Artery}

\section{Disease}

\author{
Tolga Doğan ${ }^{1 *}$, Osman Akın Serdar ${ }^{2}$, Naile Bolca Topal ${ }^{3}$ and \\ Özgür Yalçınbayır ${ }^{4}$ \\ 'Department of Cardiology, Hitit University Çorum Training and Research Hospital, Çorum, \\ Turkey \\ ${ }^{2}$ Department of Cardiology, Uludag University School of Medicine, Bursa, Turkey \\ ${ }^{3}$ Department of Radiology, Uludag University School of Medicine, Bursa, Turkey \\ ${ }^{4}$ Department of Ophthalmology, Uludag University School of Medicine, Bursa, Turkey
}

\section{ABSTRACT}

Objective: Retinal microvascular anomalies may be a marker for cardiovascular diseases. Our aim in this study was to investigate the utility of ocular fundoscopic examination as a noninvasive method in specifying the patients who carry a risk for coronary artery disease.

Material and Method: Patients who were diagnosed with coronary artery disease by coronary angiography were included in our study. Bilateral fundoscopic examination was performed in these patients. Fundoscopic findings and risk factors for coronary artery disease were evaluated.

Results: This study enrolled 100 patients (male: 72 (72\%), mean age: $58.25 \pm 7.1$ ) who were diagnosed with coronary artery disease by coronary angiography. Upon fundoscopic examination, $87 \%$ of the study population had atherosclerotic changes. Grade I atherosclerosis was found in $54 \%$ of the patients, grade II atherosclerosis was found in $32 \%$ of the patients and grade III atherosclerosis was found in $1 \%$ of the patients. Increased retinal tortuosity was present in $65 \%$ of the patients. Hollenhorst plaque was observed in 3 patients. Drusenoid bodies were observed with a statistically significantly higher rate in the patients who were not using clopidogrel compared to the patients who were using clopidogrel $(p<0.001)$

Conclusion: Retinal findings are frequently found in patients with coronary artery disease. Therefore, fundoscopic examination is a noninvasive and feasible examination method which can be frequently used in the evaluation of cardiac functions.

\section{INTRODUCTION}

Currently, coronary artery disease (CAD) is the leading cause of death in our country and in the world [1]. CAD is the fourth leading cause which will limit life in 2020 in the list prepared by the World Health Organization [2]. Retinal microvascular abnormalities which can be easily detected noninvasively reflect cumulative microvascular injury and may indicate the relationship between microvascular pathologies and cardiovascular diseases [3]. In this study, we aimed to evaluate the relationship between the risk factors for coronary artery disease and retinal findings by performing fundoscopic examination in patients diagnosed with CAD.

\section{MATERIAL AND METHOD}

This study was approved by Uludağ University, Medical Faculty, Ethics Committee on January the 20th, 2009 with the protocol number 2009-1/70. A hundred patients 
who underwent coronary angiography and diagnosed with CAD (72 men, 28 women; mean age $58,25 \pm 7,1$ years) were included in the study. The study inclusion criteria included being aged above 35 years and below 75 years and having been diagnosed with coronary artery disease by coronary angiography. The blood pressure values were measured following a resting period of ten minutes in the sitting position from the right arm using an appropriate cuff size. Two measurements were performed with an interval of two minutes and the mean value was recorded. The patients who had a SBP of $\geq 140 \mathrm{mmHg}$ and/ or DBP of $\geq 90 \mathrm{mmHg}$ and who were using antihypertensive medication were considered hypertensive [4]. The coronary risk factors were evaluated separately in the patients who were included in the study.

\section{Fundoscopic examination}

The patients were evaluated in the Opthalmology Retina Outpatient Clinic. Fundoscopic examination was performed in both eyes by the same opthalmologist using Zeiss FF 450 Plus IR fundus camera (Carl Zeiss, Meditec Inc. Jena, Germany). Before the procedure, both pupils were dilated using Tropamid Fort \%1 eye drop.

\section{Coronary angiography}

Presence of $25 \%$ or more stenosis in the major epicardial arteries on coronary angiography was considered CAD [5]. Presence of less than 50 stenosis in the epicardial coronary arteries and/or lateral coronary artery disease (having a diameter of less than $2 \mathrm{~mm}$ and supplying a small myocardial area) was considered non-critical coronary artery disease. In addition, patients who were found to have coronary ectasia without severe stenosis developing on a atherosclerotic background were also included in the study.

\section{Evaluation of carotid Intima Media Thickness (IMT)}

The patients were examined in the supine position for carotid IMT. All ultrasonographic examinations were performed by the same radiologist. $11 \mathrm{MHz}$ electronic linear probe was used (Aplio, Toshiba-Japan). Only the posterior (distant) Wall was evaluated targeting $1 \mathrm{~cm}$ proximal of the carotid bifurcatio.

\section{Obtaining blood samples}

The blood samples of our patient groups were obtained following a fasting period of 12 hours just after admission in the hemodynamics clinic in the morning from the antecubital vein by creating mild stasis in the upper arm. Serum total cholesterol (T.Chol), HDL cholesterol (HDL-C), triglyceride (TG), urea, creatinine, sodium, potassium, sedimentation, hemoglobin ( $\mathrm{Hb}), \mathrm{HbA1}$, serum reactive protein (CRP) and fasting blood glucose levels were measured. LDL cholesterol (LDL-C) was calculated using Friedewald formula (LDL Chol=T. Chol.-(HDL Chol.+TG/5) [6].

\section{STATISTICAL ANALYSIS}

Statistical analyses were performed using IBM SPSS Statistics for Windows, Version 19.0. (IBM Corp. Armonk, NY). The variables were investigated using analytical methods (Kolmogorov-Smirnov/Shapiro-Wilk test) to determine whether or not they were approximately normally distributed. Descriptive statistics were reported as mean with standard deviation for continuous variables with normal distribution, median and $25^{\text {th }}-75^{\text {th }}$ percentile values for continuous variables without normal distribution, and frequencies with percentages for the categorical variables. Group comparisons for continuous variables were tested using Student $t$ test when data distribution was normal and using Mann-Whitney $\mathrm{U}$ test when data distributions were not normal. Comparisons for categorical variables were evaluated by chi-square test. Significance level was accepted as $\mathrm{p}<0.05$ in all statistical analyses. 


\section{RESULTS}

The clinical properties and baseline biochemical values of all the patients included in the study and the drugs they used are shown in Table 1 . The study population was composed of $72(72 \%)$ male and $28(28 \%)$ female patients. While the number of smokers was $21(21 \%)$, the rate of having a familial history of CAD was found to be $22 \%$. According to the New York Heart Association (NYHA) classification, 89 patients had NYHA class I functional capacity and 11 patients had NYHA class II functional capacity. There was no patient with a NYHA class III or IV functional capacity in the study population. When use of medication of the patients was examined, the rates of the patients who were using aspirin (81\%), $\beta$ - blocker (77\%), statin $(84 \%)$ and nitrate (57\%) were found to be high.

Table 1: Baseline demographic characteristics of the study population.

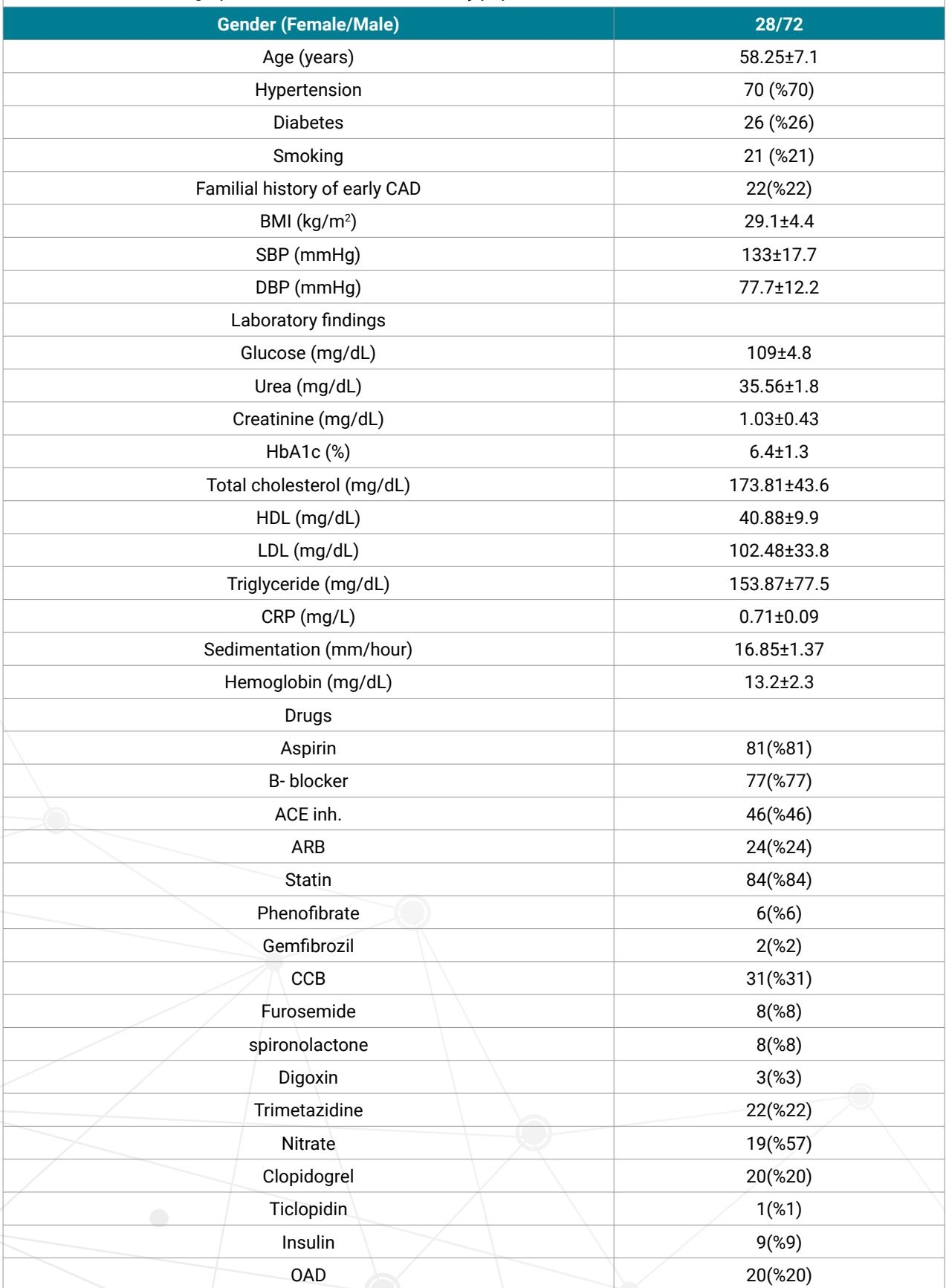

BMI: Body Mass Index, SBP: Systolic Blood Pressure, DPB: Diastolic Blood Pressure, HDL: High Density Lipoprotein, LDL: Low Density Lipoprotein,ARB: Angiotensin receptor Blocker, CCB: Calcium Channel Blocker, OAD:Oral anti-diabetic drug; CRP: Serum Reactive Protein. The values are given as mean \pm Standard deviation 
The carotid artery intima-media thickness was found to be $\geq 1 \mathrm{~mm}$ only in 17 patients in the study population and the mean right carotid artery intima-media thickness was found to be $0.765 \pm 0.15 \mathrm{~mm}$ and the mean left carotid artery intimamedia thickness was found to be $0.779 \pm 0.16 \mathrm{~mm}$. No significant correlation was found between the retinal findings and the left and right carotid artery intima-media thicknesses. Atherosclerotic changes were found on fundoscopic examination in $87 \%$ of the patients included in the study (Table 2). Grade I atherosclerosis was found in $54 \%$ of the patients (15 women, 39 men), grade II atherosclerosis was found in $32 \%$ (10 women, $22 \mathrm{men}$ ) and grade III atherosclerosis was found in 1\% (1 male patient). Grade IV atherosclerosis was not found. When the patients who did and did not have atherosclerotic retinopathy (AR) on fundoscopic examination were compared, it was found that hypertension and hyperlipidemia were observed with a higher frequency and the body mass index was higher in the patients who had retinopathy $(\mathrm{p}<0.001$ for all).

Hypertensive retinopathy (HR) was found in 95 of the patients ( 28 women, 67 men). Grade I HR was found in 53 of these patients (53\%), grade II HR was found in 30 $(30 \%)$ and grade III HR was found in $12(12 \%)$. Grade IV HR was not found. Diabetic retinopathy was found in 8 patients. HbA1c levels were significanly higher in patients with diabetic retinopathy $(\mathrm{p}<0.001)$. Critical lesions were found in coronary arteries in all patients with diabetic retinopathy. No significant difference was found when the patients were compared in terms of fundoscopic findings by coronary artery lesions.

Drusenoid bodies were found in 53 patients (Figure 1A). Retinal vein occlusion (RVO) was found in 10 patients ( 5 women, 5 men) and retinal collateral vessel formation was observed in 11 patients. Both collateral vessel formation and presence of RVO were found in 9 of these patients. Hollenhorst plaque was found in three patients (Figure 1B). Increased retinal tortuosity was found in $65 \%$ of the patients (Figure 1C). The frequency of RVO was statistically significantly higher in patients who were not using ASA $(26,3 \%)$ compared to the patients who were using ASA $(6,2 \%)$ and retinal collateral vessel formation was observed with a statistically significantly higher rate in patients who were not using ASA compared to the patients who were using ASA $(p<0.001)$. Among fundoscopic findings, drusenoid bodies were found with a significantly higher rate in patients who were smokers $(\mathrm{p}<0.001)$. Similarly, drusenoid bodies were found with a statistically significantly higher rate in patients who were not using clopidogrel compared to the patients who were using clopidogrel $(\mathrm{p}<0.001)$.

\section{DISCUSSION}

Evaluation of the coronary and cerebral circulation and the retinal vessels which have similar anatomic and physiological characteristics can be performed by way of fundoscopic examination which is a feasible and non-invasive method [7]. Many studies have proposed that atherosclerotic changes found in the retina may be a marker of the prevalence of coronary artery disease [8]. In a large-scale study, it was found that the risk of congestive heart failure was increased by three-fold in patients with retinopathy who had no coronary artery disease and hypertension [9]. In another

Table 2: Fundoscopic Examination Findings of the Patients (expressed as percentages).

\begin{tabular}{|c|c|}
\hline Fundoscopic Findings & $(\mathbf{n}, \%)$ \\
\hline Atherosclerosis & $(87 \% ; 54 \%$ Grade I, 32\% Grade II, 1\% Grade III) \\
\hline Hypertensive Retinopathy & $(95 \% ; 53 \%$ Grade I, 30\% Grade II, 12\% Grade III) \\
\hline Retinal Vein Occlusion & $(10 \%)$ \\
\hline Presence of Retinal Collateral Vessels & $(10 \%)$ \\
\hline Retinal tortuosity & $(65 \%)$ \\
\hline Hollenhorst & $(3 \%)$ \\
\hline Drusenoid bodies & $(52 \%)$ \\
\hline
\end{tabular}


study, the relationship of retinal vascular changes with left ventricular mass, left ventricular volume and concentric remodeling was investigated and it was stated that microvascular disease contributed to formation of cardiac remodeling by correlating with the risk factors of coronary artery disease [10].

In our study, Scheie classification was used in evaluation of AR and HR [11]. Our results showed that AR was closely related with hypertension, hyperlipidemia and BMI which are among the coronary artery disease risk factors similar to previous studies. Besides, the distribution of HR was similar to the distribution of AR in this study.

Point opacities were observed on the retinal surface in $52 \%$ of our patients. When funduc camare was used, it was thought that these opacities were drusenoid bodies (Figure 1A). It was thought that the drusenoid bodies which were found with a high rate in our study might be small drusens related with age-related macula degeneration (ARMD) and/or particles located in the retina by way of extravasation of intravascular cholesterol crystals. ARMD is the most common legal cause of blindness in the population aged 65 years and older [12]. In all studies, the prevalence of ARMD has shown an increase with age. Atherosclerosis in the carotid vascular bed, presence of systemic hypertension, smoking and dislipidemia are risk factors for development of ARMD $[13,14]$. Similarly, drusenoid bodies were found with a statistically significantly higher rate in patients who were smokers in our study.

The frequency of usage of clopidogrel is increasing in the cardiovascular area. In previous studies, ASA and the other non-steroidal anti inflammatory drugs were not shown to decrease the risk of ARMD [15]. Similarly, no significant difference was found between the patients who were and were not using ASA in terms of drusenoid bodies in our study. However, these bodies were observed with a significantly higher rate in the patients who were not using clopidogrel compared to the patients who were using clopidogrel. If these bodies are considered drusen bodies related with ARMD, it may be thought that clopidogrel decreases development of ARMD in patients with a high risk in terms of coronary artery disease. In a study conducted by Cymerman et al. with young patients who had coronary artery disease, it was found that reticular macular disease which is a subtype of ARMD was observed commonly in middle-aged patients with coronary artery disease. In contrast to our study, it was emphasized that there was no significant correlation between CAD and drusen bodies. It was

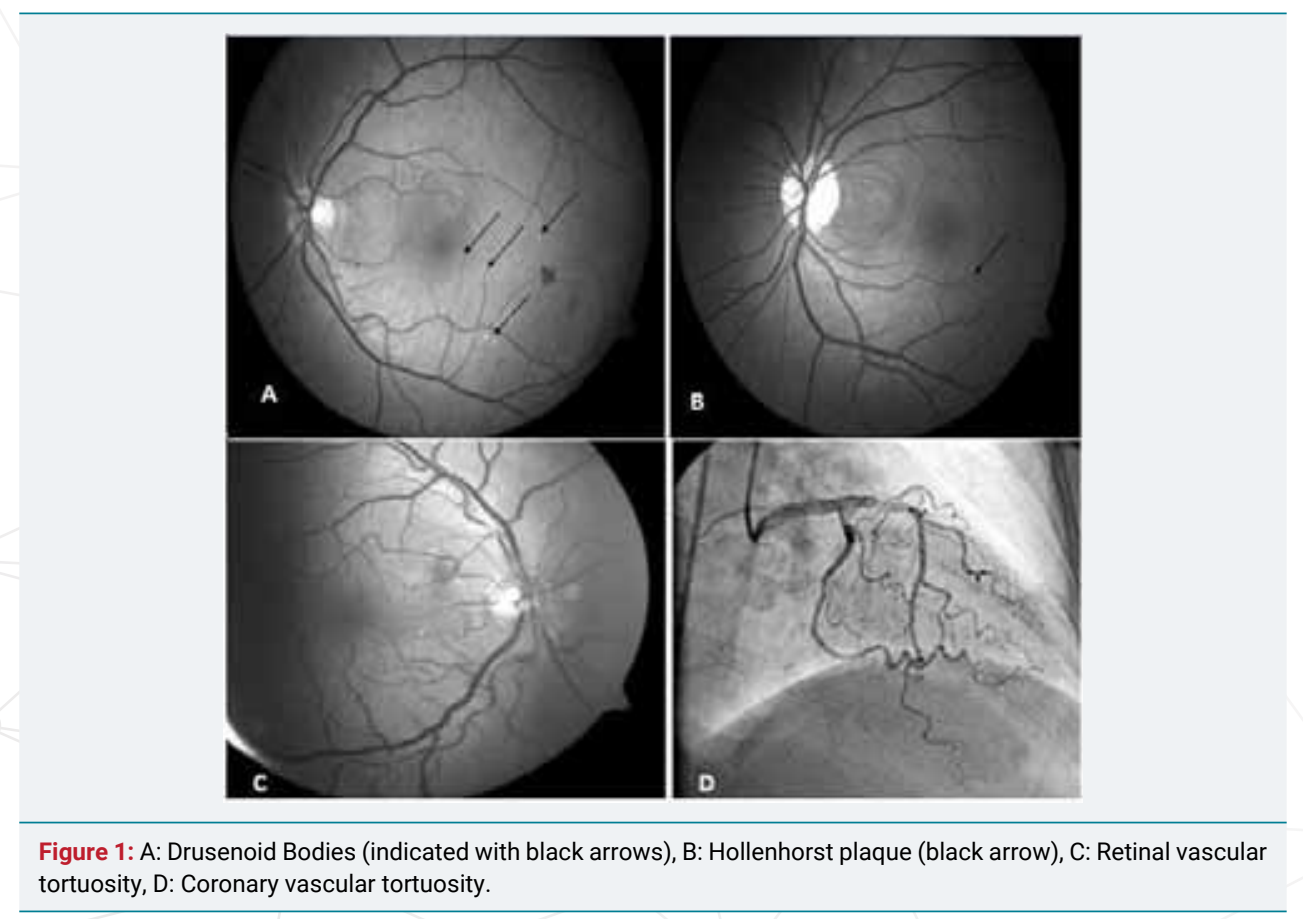


emphazsied that the relationship of reticular macular disease with CAD was related with subretinal drusenoid deposits found between the retinal pigment epithelium and internal segment ellipsoid region similar to the lipid mechanism in atherosclerosis [16]. More and extended studies are needed to elucidate the relationship between reticular macular diseases and CAD.

As known, increased tortuosity in the arteries occurs as a result of aging or pathological changes in vascular elastic material [17-20; Figure 1D]. It has been reported that atherosclerosis, hypertension and aging play a role in development of arterial tortuosity [21-23]. Increased tortuosity in the retinal arteries occurs as a result of aging or pathological chenges in vascular elastic material $[24,25]$. Increased tortuosity may also be observed in the retinal arteries. It is known that this is observed frequently especially in retin al pathologies including diabetic retinopathy, retinal vein occlusion and retinal vasculitis. In a study conducted by Owen et al., a relationship was shown between increased cholesterol (especially increased triglyceride level) and blood pressure (risk factors for coronary artery disease) in the first 10 years of the childhood and tortuosity in the retinal arteries [26]. Presence of retinal tortuosity in 65 of 100 patients with coronary artery disease in our study supports this study.

One of the findings examined in our study was Hollenhorst plaques. Hollenhorst plaques are one of the most frequent causes of retinal emboly [27]. These are orange, refractile cholesterol cryrstals with a length of 10-250 $\mu \mathrm{m}$ and constitute the fundoscopic finding of Cholesterol Embolization Syndrome (CES) [28,29]. In our study, Hollenhorst plaques were found in three patients (a woman and 2 men). One of these patients had a history of thrombolytic treatment and the other one had a history of coronary bypass surgery. All three patients were hypertensive. Patients with Hollenhorst plaques on ophthalmologic examination are in the high risk group in terms of morbidity and mortality. The most appropriate mechanism explaining CES syndrome related with thrombolytic agents includes dissolving of protective thrombin coagulum with thrombolytic agents and release of cholesterol crystals because of subintimal hemorrhage [30].

IMT is an indicator of generalized atherosclerotic process which also involves the coronary arteries. Relationship of CAD with many risk factors shows mutual pathophysiological mechanisms of atherosclerosis [31]. In the ARIC study, an IMT value of $\geq 1 \mathrm{~mm}$ was found to be related with an approximately 5 -fold higher rate of stroke compared to an IMT value of $<0.6 \mathrm{~mm}$ [32]. In our study, the right and left carotid IMT rates of the patients were observed to be within the normal limits [33]. One of the reasons of the fact that marked increase in the carotid IMT value was not observed might be related with life style change and the fact that most patients had been using lipid lowering treatment.

The limiting factor of our study was the fact that only patients with coronary artery disease were included without a control group (patients with normal coronary arteries). Studies with a larger number of patients including a control group are needed to evaluate retinal vascular changes more comprehensively in patients with coronary artery disease.

In conclusion, fundoscopic examination is a non-invasive method which can be performed easily in patients with coronary artery disease. Collaboration of cardiologists and opthalmologist in evaluation of coronary artery diseases and cardiovascular risk factors may profide a more efficient approach in diagnosis and treatment of these diseases.

\section{REFERENCES}

1. Bonow RO, Smaha LA, Smith SC Jr, Mensah GA, Lenfant C. World Heart Day 2002: the international burden of cardiovascular disease: responding to the emerging global epidemic. Circulation. 2002; 106: 1602-1605. Ref.: https://goo.gl/QLe28G 
2. 2nd World Health Report 1999: Making a difference. Geneva: World Health Organization; 1999.

3. Goto I, Katsuki S, Ikui H, Kimoto K, Mimatsu T. Pathological studies on the intracerebral and retinal arteries in cerebrovascular and noncerebrovascular diseases. Stroke. 1975; 6: 263-269. Ref.: https://goo.gl/vfNrvL

4. Tedeschi-Reiner E, Strozzi M, Skoric B, Reiner Z. Relation of atherosclerotic changes in retinal arteries to the extent of coronary artery disease. Am J Cardiol. 2005; 96: 1107-1109. Ref.: https://goo.gl/USq7Uc

5. Baim DS, Grossmann W. Coronary Angiography. In: Baim Grossmann, editor. Grossman's Cardiac Catheterization, angiography, and Intervention. 6th ed. Philadelphia: Lippincott Williams and Wilkins; 2000; 211-257.

6. Friedewald WT, Levy RI, Fredrickson DS. Estimation of the concentration of low-density lipoprotein cholesterol in plasma, without use of the preparative ultracentrifuge. Clin Chem. 1972; 18: 499-502. Ref.: https://goo.gl/e2Nb9g

7. Apple DJ, Naumann GO. Retina, In: Naumann GO, Apple DJ (eds). Pathology of the Eye. New York; Springer-Verlag; 1986; 580-583.

8. Tedeschi-Reiner E, Strozzi M, Skoric B, Reiner Z. Relation of atherosclerotic changes in retinal arteries to the extent of coronary artery disease. Am J Cardiol. 2005; 96: 1107-1109. Ref.: https://goo.gl/KEskQ9

9. Torpy JM, Glass TJ, Glass RM. JAMA patient page. Retinopathy. JAMA. 2005; 293: 128. Ref.: https://goo.gl/c4pwhU

10. Cheung N, Bluemke DA, Klein R, Sharrett AR, Islam FM, et al. Retinal arteriolar narrowing and left ventricular remodeling: the multi-ethnic study of atherosclerosis. J Am Coll Cardiol. 2007; 50: 48-55. Ref.: https://goo.gl/e62Arb

11. Lang GK. Ophthalmology: A Pocket Textbook Atlas. (Thieme, Stuttgart, 2007).

12. Kelin R. Epidemiology. In age-related macular degeneration. In: Berger JW, Fine SL, Maguire MG. Eds. Philadelphia: Mosby. 1999; 31-55.

13. Klein R, Klein BE, Linton KL, DeMets DL. The Beaver Dam Eye Study: the relation of age-related maculopathy to smoking. Am J Epidemiol. 1993; 137: 190-200. Ref.: https://goo.gl/Pnadtb

14. Smith W, Mitchell P, Leeder SR. Smoking and age-related maculopathy. The Blue Mountains Eye Study. Arch Ophthalmol. 1996; 114: 1518-15123. Ref.: https://goo.gl/EBmPbX

15. Christen WG, Glynn RJ, Ajani UA, Schaumberg DA, Chew EY, et al. Age-related maculopathy in a randomized trial of low-dose aspirin among US physicians. Arch Ophthalmol. 2001; 119: 1143-1149. Ref.: https://goo.gl/GcBGYG

16. Cymerman RM, Skolnick AH, Cole WJ, Nabati C, Curcio CA, et al. Coronary Artery Disease and Reticular Macular Disease, a Subphenotype of Early Age-Related Macular Degeneration. Curr Eye Res. 2016; 41: 1482-1488. Ref.: https://goo.gl/YpiKih

17. Ertugrul A. Diffuse tortuosity and lengthening of the arteries. Circulation. 1967; 36: 400-407. Ref.: https://goo.gl/hJE7ww

18. Soikkonen $\mathrm{K}$, Wolf $\mathrm{J}$, Hietanen $\mathrm{J}$, Mattila $\mathrm{K}$. Three main arteries of the face and their tortuosity. $\mathrm{Br} \mathrm{J}$ Oral Maxillofac Surg. 1991; 29: 395-398. Ref.: https://goo.gl/fx5MG6

19. Dobrin PB, Schwarcz TH, Baker WH. Mechanism of arterial and aneurysmal tortuosity. Surgery. 1988; 104: 568-571. Ref.: https://goo.gl/DWGbqU

20. Zegers ES, Meursing BTJ, Zegers EB. A.J.M oude ophuis coronary tortuosity: a long and winding road. Neth Heart J. 2007; 15: 191-195.

21. Leipzig TJ, Dohrmann GJ. The tortuosity or kinked carotid artery: pathogenesis and clinical considerations. Surg Neurol. 1986; 25: 478-486. Ref.: https://goo.gl/w9NvFh

22. Weibel J, Fields WS. Tortuosity, coiling, and kinking of the internal carotid artery: etiology and radiographic anatomy. Neurology. 1965; 15: 7-18. Ref.: https://goo.gl/3rtiFG

23. Del Corso L, Moruzzo D, Conte B, Agelli M, Romanelli AM, et al. Tortuosity, kinking, and coiling of the carotid artery: expression of atherosclerosis or aging? Angiology. 1998; 49: 361-371. Ref.: https://goo.gl/ZwVtMa

24. Zegers ES, Meursing BT, Zegers EB, Oude Ophuis AJ. Coronary tortuosity: a long and winding road. Neth Heart J. 2007; 15: 191-195. Ref.: https://goo.gl/PcfZVY

25. Del Corso L, Moruzzo D, Conte B, Agelli M, Romanelli AM, et al. Tortuosity, kinking, and coiling of the carotid artery: expression of atherosclerosis or aging? Angiology. 1998; 49: 361-371. Ref.: https://goo.gl/ZwVtMa

26. Owen CG, Rudnicka AR, Nightingale CM, Mullen R, Barman SA, et al. Retinal arteriolar tortuosity and cardiovascular risk factors in a multi-ethnic population study of 10 year old children; the Child Heart And health Study in England Arterioscler Thromb Vasc Biol. 2011; 31: 1933-1938. Ref.: https://goo.gl/z6BBHh 
27. Brown GC, Magargal LE. Central retinal artery obstruction and visual acuity. Ophthalmology. 1982; 89: 14-19. Ref.: https://goo.gl/JfGTwF

28. David NJ, Klintworth GK, Frieldberg SJ, Dillon M. Fetal Atheromatous cerebral embolism associated with bright plaques in the retinal arterioles. Report of a case. Neurology. 1963; 13: 708-713. Ref.: https://goo.gl/XmP6AL

29. Hollenhorst RW, Lensink ER, Whisnant JP. Experimental Embolization of the Retinal Arterioles. Trans Am Ophthalmol Soc. 1962; 60: 316-334. Ref.: https://goo.gl/ryZffo

30. Scolari F, Bracchi M, Valzorio B, Movilli E, Costantino E, et al. Cholesterol atheromatous embolism: an increasingly recognized cause of acute renal failure. Nephrol Dial Transplant. 1996; 11: 1607-1612. Ref.: https://goo.gl/pNArPE

31. Poli A, Tremoli E, Colombo A, Sirtori M, Pignoli $\mathrm{P}$, et al. Ultrasonographic measurement of the common carotid arterial wall thickness in hypercholestrolemic patients. Athresclerosis.1988; 70: 253-261. Ref.: https://goo.gl/FgjVC4

32. Chambless LE, heiss G, Folsom Ar, rosamond W, Szklo M, et al. Association of coronary heart disease incidence with carotid arterial wall thickness and major risk factors: the Atherosclerosis Risk in Communities (ARIC) Study, 1987-1993. Am J Epidemiol. 1997; 146: 483-494. Ref.: https://goo.gl/ruU6GR

33. P Nikic, M Savic, V Jakovljevic, D Djuric. Carotid atherosclerosis, coronary atherosclerosis and carotid intima-media thickness in patients with ischemic cerebral disease: Is there any link? Exp Clin Cardiol. 2006; 11: 102-106. Ref.: https://goo.gl/q45uLs 